\title{
Stress and Rhythm in English
}

\author{
Maria-Josep Solé Sabater \\ Universidad Autónoma de Barcelona
}

\begin{abstract}
This paper studies the role played by stress and rhythm in English. The effects of stress on the phonetic realization of segments, the morphological and syntactic function of elements and the structuring of information in the sentence are considercd. English rhythm is studied and the factors that contribute to maintain a regular stress-timed rhythm are presented. A rhythmical approach to English pronunciation is proposed, which involves the practice of pronunciation in terms of stressing and unstressing and in longer stretches of speech. Finally, some material for practising English stress and rhythm is presented.
\end{abstract}

\section{Introduction}

In English teaching practice the study of pronunciation basically concentrates on the segmental aspects of English: the practice of phoneme contrasts and phoneme sequences. The practice of English stress and rhythm has been traditionally neglected despite the existence of (i) a number of descriptions in an English teaching framework of English word stress (Kingdon, Fudge), sentence stress (Albrow) and rhythm (Classe, Brown, Couper-Kuhlen), and (ii) practice materials (Guierre, Tibbits, O'Connor and Arnold and Tooley, amongst others). An appropriate stress and rhythmic pattern is more important for intelligibility than the correct pronunciation of isolated segments and, in fact, stress and rhythm determine the pronunciation of segments in English.

Stress and rhythm are suprasegmental aspects that give the overall shape to the word or sequence. If easy intelligibility is to be achieved, it is important to give words their correct accentual pattern and rhythm. Thus, the pronunciation of a word with the inappropriate accentual and rhtyhmic pattern, for example:

vocabulary [və'kæbjuləri] as [voka'bjulari]

profitable ['profitəbl] as [profi'teibol]

makes the word unintelligible not only because the misplaced main stress distorts the shape of the word, but also because there is no unstressing of the other syllables with 
the consequent phonetic reductions. The inappropriate pronunciation of a single word, however, is not vital for intelligibility since in most cases the right form of the word can be reconstructed from the context. This issue becomes more important at the phrase level. If an English sentence is pronounced without the appropriate weakening of unstressed syllables and unaccented grammatical words, a serious loss of intelligibility results. Thus, the sentence you should have come to the library is less easy to understand when pronounced ['ju: ' $\mathrm{ud}$ 'hæv ' $\mathrm{k} \wedge \mathrm{m}$ 'tu: ' $\mathrm{\delta} i$ : 'laibrəri] than if it is pronounced [ju $\int \partial \mathrm{d} \partial \mathrm{v}$ ' $\mathrm{k} \Lambda \mathrm{m}$ tə $\delta \partial$ 'laibrəri]. In other cases, a misunderstanding might result from the lack of weakening of unstressed syllables. Thus, if a foreign speaker pronounces the sequence These books are mine with no unstressing [' $\mathrm{Oi}: \mathrm{z}$ 'buks 'a: 'main], this sentence will be heard as these books aren't mine since only negated auxiliaries can be stressed in English (in non-contrastive pronunciation). Thus, the sequence will be interpreted as the result of the dropping of the final interconsonantal [t] (1), assimilation of the alveolar nasal to the following labial (2), and reduction of the labial closure duration (3):

(1) [oi:z 'buks 'a:n(t) 'main]

(2) [סi:z 'buks 'a:m 'main]

(3) [סi:z 'buks 'a:(m)'main]

Consequently, assigning the right stress pattern-at the word and phrase level-and learning to produce unstressed syllables is the most productive single device for achieving an adequate pronunciation of English.

In this paper we propose a rhythmical approach to English pronunciation which involves the practice of pronunciation in terms of stressing and unstressing and in longer stretches of speech-which will contribute to more meaningful communication. This will help to instil a sense of English rhythm in the learner and to improve his overall pronunciation of English. Since no English word or sentence can be uttered without a stress and rhythmic pattern, we suggest that teachers should practice the appropriate realization of the stress and rhythmic pattern of the sentence right from the first pronunciation sessions. Since stress and rhythm determine the pronunciation of consonants and vowels - as will be shown below-many segmental problems will not come up if stress and rhythmic exercises are practised in the early stages. Brown (51) points out the problems involved in practising segmental aspects prior to practising stress and rhythm. For example, after painstaking efforts the Spanish student might succeed in producing a «difficult» sound, e.g. $\left[\mathrm{d}_{3}\right]$ in Janet, which he might carefully pronounce ['d $\mathrm{d}_{3} \mathrm{e}^{-} \mathrm{net}$ ]. When the right rhythmic pattern (stress and weakening of unstressed syllables) is required, the student concentrates on the stress pattern and he produces a suspicious ['jænət]. Thus, it proves to be more adequate to first acquire the appropriate stress pattern and then deal with the segmental problems that might still persist. In fact, this approach correlates with the way in which the first language is acquired. Children at early stages tend to repeat and produce from the stressed syllable onwards, which shows that they acquire the stress pattern (and intonational pattern) before the actual realization of segments.

In the following sections we will first consider the effects of stress at different levels of the language--segmental, morphological, syntactical and lexical-which will 
make clear the pervasive effect of stress and the importance of teaching English pronunciation in terms of stressing and unstressing. In section 2 we will consider the physical nature of stress and unstress and the distribution of word stress and sentence stress in English. Section 3 will concentrate on English rhythm and in the last section we will suggesi some exercises to practise stressing and unstressing in English.

\section{Linguistic Phenomena Sensitive to Stress}

Stress and rhythm are the backbone of English pronunciation. The role of stress, however, goes far beyond the segmental and suprasegmental levels. English stress has a bearing on syllable structure, morphology, grammar and meaning. We will next consider briefly the different areas which are sensitive to stress.

\subsection{Segmental Effects of Stress}

The phonetic realization of segments largely depends on their position with respect to stress. The clearest case is the relationship between stress and vowel quality. Stressed vowels have their full vowel quality, while the same vowels in unstressea position will be reduced to [ə] or the reduced vowels [i, u], e.g. 'present ['prezənt] vs pre'sent [pri'zent]. Stress affects not only vowels but the whole syllable. Consequently consonants in unstressed syllables will suffer important reduction processes. Next we illustrate some regular phonological processes due to stress.

The voiceless stops $/ \mathrm{p}, \mathrm{t}, \mathrm{k} /$ are aspirated in the words apart, take and come [ $\partial^{\text {' }} \mathrm{p}^{\mathrm{h}} \mathrm{a}: \mathrm{t}$, 'theik, ' $k^{\mathrm{h}} \wedge \mathrm{m}$ ], but not in the words polite, tonight and baking [pə'lait, tə'nait, 'beikig]. The realization of $/ \mathrm{p}, \mathrm{t}, \mathrm{k} /$ in the two sets of words differs because of stress. $/ \mathrm{p}, \mathrm{t}, \mathrm{k} /$ are aspirated if they occur as the initial element in a stressed syllable and they are unaspirated in an unstressed syllable. Thus, the determining factor for aspiration vs lack of aspiration is stress.

Similarly, $/ \mathrm{t} /$ and $/ \mathrm{d} /$ in the words atom and Adam can be flapped in many dialects of English, and thus these two words may coincide in the pronunciation ['ærəm]. However, the [t] and [d] in atomic, attract and endeavour can never be flapped. This is due to the effect of stress; [t] and [d] can be flapped (i) between a stressed vowel and an unstressed vowel, e.g. 'atom [ $\Omega$ ], and (ii) between vowels that have the same degree of stress, both unstressed as in di'vinity [ $[$ ], or both stressed as in 'not 'all $[r] . / t /$ and /d/ cannot be flapped, however, if the preceding vowel is more weakly stressed than the following vowel, e.g. a'tomic, a'ttract.

The fricatives $[\mathrm{v}, \mathrm{f}]$ in the words divine, fine have more friction noise than in the words ivy or dolphin, because in the first set of words they occur in a stressed syllable. Similarly, the fricatives $[\mathrm{v}, \delta]$ can lose their friction completely, and even disappear altogether in unstressed syllables of very frequent sequences, e.g. cup of tea [kıpə'ti:], what's the matter ['wotsə'mætə].

The prosodic device of introducing a glottal stop before a word initial vowel for emphatic reasons, as in that's 'awful, is only possible if the vowel is stressed. The 
similarly emphatic utterance that's amazing can never show a reinforcing glottal stop before the unstressed initial vowel. Since a number of allophonic realizations depend on stress, it is essential to learn the stress pattern of a word to pronounce the segments adequately.

\subsection{Phonological Variation Due to Stress}

Stress might determine the occurrence of different phonemes. Thus the pronunciation of the letter $x$ as [ks] or [gz] in words such as exit ['eksit], exhibition [,eksi'bi n], and exist [ig'zist], exhibit [ig'zibit] is determined solely by the position of the stress. If the stress is on the preceding syllable the cluster will be voiceless; if the stress is on the following syllable the cluster will be voiced. A parallel effect of stress on voicing can be seen in Verner's law whereby Germanic voiceless fricatives became voiced when the Indo-European stress was not on the preceding syllable (thus *IE pəter $>$ Germanic * fáthar $[\theta]>$ voiced fádar $[\delta])$.

\subsection{Syllable Structure and Stress}

English syllable structure is a controversial issue, however, most current theories recognize the role played by stress in determining syllable structure and syllable boundaries. Stressed vowels attract adjacent consonants to their syllable. Thus, English consonants tend to be syllabified with the more strongly stressed syllable:
attic ['æt-ik]
attain [ə-'tein]
sister ['sist-ə]
astound [ə-'staund]

Observe how the stress shift involves a change in syllable boundary and syllable affiliation of $/ \mathrm{t} /$ and $/ \mathrm{d} /$ in the following words:

$$
\begin{array}{ll}
\text { atom ['æt- } \mathrm{m}] & \text { atomic [ə-'tom-ik] } \\
\text { adaptation ['æd-əp-'tei -n] } & \text { adapt [ə'-dæpt] }
\end{array}
$$

In the words in the first column /t, $d /$ syllabify with the stressed syllable and consequently they occur in syllable final position. The test for syllable final position is (i) that they can be flapped to $[\varsigma]$ in some dialects (e.g. American English): ['æ $\varsigma$ əm], [,æৎəp'teifn], and (ii)/t/ can be pregottalized in other dialects (e.g. Cockney): ['æ'təm]. $/ \mathrm{t}, \mathrm{d} / \mathrm{cannot}$ be flapped or preglottalized in a'tomic or a'dapt. In the words in the second column, $/ \mathrm{t}, \mathrm{d} /$ syllabify with the following stressed syllable, and they are initial elements in the syllable. $/ t$ / is shown to be syllable initial since it is aspirated, [ $\partial^{\prime} t^{\mathrm{h}}$ omik] while there is no heavy aspiration in atom. Thus, stress can be said to determine the grouping of sounds into syllables in English. 


\subsection{Morphological, Syntactical and Lexical Variation Due to Stress}

There are a number of morphological alternations that affect stress and, consequently, the pronunciation of the whole word. Morphological derivation might involve a change in stress since many of the suffixes which are added to derive words have an effect on stress. The words:

$$
\text { 'politics po'litical poli'tician }
$$

illustrate how the adjectival suffix -al moves the stress to the second syllable, and the nominal suffix -ian shifts the stress to the syllable preceding it. There are also suffixes that attract the stress of the word on to themselves, such as -aire in 'question, 'questio'nnaire, or -ette, in 'usher, 'ushe'rette. The effect of suffixes on stress can be predicted by a finite set of rules (see Fudge, Kreidler).

Another function of stress is to indicate the syntactic function of the word. The stress and subsequent phonetic changes are the only indicator of the syntactic category of words such as a 'present, to pre'sent; a 'frequent (word), to fre'quent; a 'record, to re'cord. The noun or adjective always has the stress on the first syllable, and the verb on the second syllable.

There is also a small number of words where stress indicates a lexical contrast that does not correlate with the syntactic function of the word: 'billow vs be'low, 'reefer vs re'fer.

Stress also differentiates between phrasal verbs, which function together as a unit and have the main stress on the particle (e.g. the 'driver pulled 'up [stopped], the 'car went 'by [passed]) and prepositional verbs which have the stress on the verb and the preposition is unstressed: he 'pulled his 'trousers up, he 'went by the 'highway. Stress also plays a role in differentiating between nouns derived from phrasal verbs and verbs. In the nouns and adjectives the first element only is stressed: $a$ 'handout, $a$ 'runaway, $a$ 'dropout. In the corresponding verbs the particle has more prominence than the verb: to hand 'out, to run a'way, to drop 'out.

The difference between compounds, such as a 'loud,speaker (sound amplifier), and noun phrases, $a$,loud 'speaker (a person who talks loud), is also indicated by stress alone. Noun phrases have the main stress on the most important element, the noun. Compounds have the main stress on the first element; in fact, stress welds together the two elements in the compound into a single lexical category with a special meaning and function. In fact, the degree of compounding of a frequently used phrase is indicated by the stress pattern.

Stress is also an indicator of the psychological reality of the morphemes that make up compound words. If the word is a morphemically transparent word, i.e. speakers recognize the two morphemes or words in the compound, both elements retain a certain degree of stress, e.g. 'Disney'land [lænd], 'mouth'ful [ful]. If speakers do not recognize the morphemic made-up of the word, but they interpret it as one single morpheme, the word retains a single stress (on the first element of the compound) with the subsequent phonetic reductions. Thus, 'England [lənd] (historically/Angle/+/land/) and 'awful [fl] (historically /awe/ $+/ \mathrm{ful} /$ ) are not interpreted as composed of two morphemes anymore, but as a single morpheme. Not all cases of compounding can be accounted for in these 
terms. However, cases such as the ones presented show that stress might correlate with psychologically real morphemes, and that each recognized morpheme bears a stress.

Still another aspect of a slightly different nature is that concerning the grammatical difference between the strong and weak forms of some words. In this case it is the presence or absence of stress which indicates the syntactic function of the word. For example, that as a demonstrative always has the full form, e.g. I 'want 'that 'book

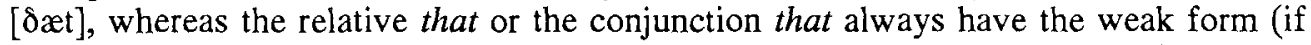

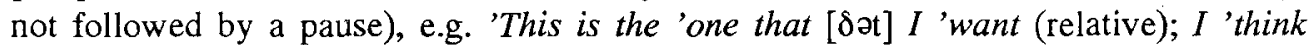

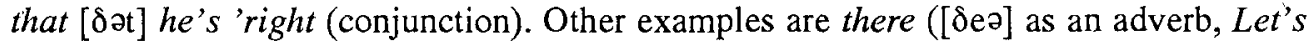

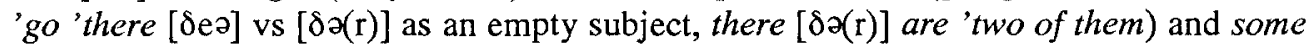
([səm] as an indefinite adjective, 'I'll have some [səm] biscuits vs [sım] as a pronoun: I'll 'have some [s $\wedge \mathrm{m}]$, or when it means 'a certain quantity of': 'Some [s $\mathrm{sm}]$ 'students were 'there, but 'not 'all).

The effects of stress at the segmental and lexical level show the importance of stress not only for what it contributes to the correct pronunciation of English at the segmental and suprasegmental level, but for its effects on intelligibility due to its lexical and syntactic function. It follows from this that practising English pronunciation in terms of stressing and unstressing should be a rewarding task.

\section{Stressing and Unstressing}

The physical correlates of stress are pitch, duration and loudness. Experimental evidence (Fry «Duration and Intensity» «Experiments,» Bolinger, Lieberman, Solé) shows the interrelation of these three parameters in the production and perception of stress. The pitch of stressed vowels is usually higher than that of unstressed vowels. Nevertheless, a syllable with a lower pitch than the rest is likely to be heard as stressed. Thus, the primary cue for stress perception (Fry «Experiments,» Bolinger, Solé) seems to be that the stressed syllable stands out in pitch from the rest. Stressed vowels also tend to have a longer duration and to be louder than unstressed vowels. In English there is an extra cue for stress which is vowel quality, in particular the reduced quality $([\partial, \mathrm{i}, \mathrm{u}])$ of unstressed syllables. Thus, stress is a relational feature. A syllable is identified as stressed because it is relatively more prominent than the rest. In English, stress is cued not only by how we use the features of pitch, duration, loudness and vowel quality in the stressed syllables, but also by how these features are used, in a reduced manner, in background or unstressed syllables. Thus, Spanish learners should practice reducing unstressed syllables in order to make the stressed syllables prominent.

\subsection{Word Stress and Sentence Stress}

Stress is present at the word level and at the sentence level. Every word said in isolation has a stress. Word stress has a fixed distribution; it is a lexical feature of the word and consequently word stress is related to the lexicon. English stress is a distinctive feature in a word. If stress changes, meaning might change, e.g. a 'present, 
to pre'sent. Recent work in generative phonology has stated rules for predicting stress assignment in words based on (1) the simple or complex (derivatives and compounds) morphological nature of the word, (2) the syntactic category of the word (noun, verb, adjective, etc.), (3) the number of syllables in a word, and (4) the phonological structure of the syllable (for a simple account of these rules see Kreidler 197-218). The rules, however, are complex and have exceptions, so it seems more adequate for the foreign learner to learn the stress pattern of the word when the word is learned (i.e. as a lexical feature of the word). As the learner advances in his mastering of English he will be able to abstract the general rules of stress assignment and correctly stress most new words he might come across.

It seems that one of the ways in which we store words in our mental lexicon is according to its stress pattern. Thus, we find it difficult to interpret a word pronounced with the wrong stress pattern; in processing this word we begin to look up possible words under this wrong stress pattern which will fit the context, and we might arrive at the wrong interpretation or we might not find an appropriate word and we may start wondering about the stress pattern. However, the first choice for interpreting the word is the stress pattern produced.

Other types of evidence for the storage of words under stress pattern comes from experimental research done on 'tip of the tongue' phenomena and 'slips of the tongue.' Tip of the tongue phenomena, that is, not being able to remember a given word but having it 'on the tip of your tongue,' show that in some cases speakers might not be able to retrieve a word but they can tell the stress pattern of the word. This suggests that in looking for the word they are activating that part of the vocabulary that has this stress pattern, and that consequently words are stored according to that pattern. Slips of the tongue or the transposition of two or more sounds show that the most common type of tongue slip involves the transposition of stressed syllables-he was on the nerve of a vergeous breakdown instead of he was on the verge of a nervous breakdown.

Every word said in isolation has a stress; however when words are put together in a sentence only some words are stressed. Sentence stress emphasizes the portion of the utterance that is more important for the speaker or that the speaker wants the listener to concentrate on. Stress in a sentence has no fixed distribution. It is related to semantics. The words which are likely to be more prominent and to carry a stress in connected speech are those which are most important for meaning, i.e. content words or lexical words, such as nouns, adjectives, verbs and adverbs. Grammatical or function words, such as articles, pronouns, prepositions, auxiliaries and conjuntions, tend to be unstressed (see Kingdon for a detailed description). Thus, in the sentence: 'Mary would have 'liked to a'ttend the 'meeting the content words Mary, liked, attend, meeting are likely to be stressed and the function words unstressed. Thus, the function of stress in sentences is to highlight the information-bearing words in the utterance.

Note that this general rule-content words are stressed, grammatical words unstressed-applies to «normal,» default stressing. It does not apply when contrastive or emphatic meaning is intended. In fact, any word or syllable might be stressed (in fact, bear the intonational nucleus) when used contrastively (but she 'was here [she hadn't left]; I said that word was 'unstressed [not stressed]) or emphatically (She's 'very nice). 


\subsubsection{Stressing and Meaning}

There is no one «right» way of stressing an English sentence. The choice to stress some words rather than others depends on the context of the message and on the particular meaning the speaker wants to convey. Consider, for example,

a) I 'don't think I can 'do it (you'd better ask another person)

b) I 'don't 'think I can 'do it (you'd better ask another person)

The stressing in these alternatives is equally acceptable. The choice of one or the other pattern depends on the attitude of the speaker towards some aspect of the message; for example, in (b) the speaker sounds less assertive than in (a). By stressing think rather than don't alone he softens the negative, suggesting that it is his momentary, subjective impression that he can't do it, and he seems to leave the possibility to be convinced a bit more open than in a). Therefore, whereas there are certain words which one would expect to find stressed in this message-don't, do-there might be different possibilities of stressing some of the words in different contexts.

Since stress has the function of signalling to the native speaker the most important words in the utterance, it is very difficult to understand speech in which every single word is stressed or made equally prominent, just because nothing is made prominent. That is why in English it is very important for intelligibility what you do to the unstressed syllables to make the stressed syllables-those of meaningful words-stand out.

\subsubsection{Stressing and Tempo}

Another factor that might affect sentence stress is tempo or speaking rate, which is related to speaking style. The more careful the style, the slower the tempo and the more stresses. The more informal the style, the faster the tempo and the fewer stresses. Consider the sentence:

a) I 'would have 'liked to a'ttend the 'meeting

b) I would have 'liked to attend the 'meeting

(a) involves a very slow and deliberate speaking rate whereas (b) demands a very fast speaking rate which accounts for the missing stresses. In fact, the more stresses you have in an utterance, the more weight you are assigning to each part of the utterance. Compare the angry and weighty tone conveyed by stressing every single word in the utterance: 'you 'will 'do 'as 'I'say.

Since informal fast speech has fewer stresses and consequently more unstressed syllables, it is most probably the most difficult style to master for the foreign student. In his attempt to sound clear, the foreign student tends to overstress words in sequence. It is consequently very important to practise unstressing if foreign speech is to sound not only intelligible but also adequate to the situation. 


\section{English Rhythm}

Speech, as with all bodily movements such as breathing, walking, heart-beat, etc., is highly rhythmical; it tends to have a regular beat. But what marks the beat differs is various languages. Pike distinguished two kinds of rhythm in languages: (i) syllable-timed rhythm, where syllables tend to occur at regular intervals of time, and consequently all syllables tend to have the same length (e.g. Spanish and French) and (ii) stressed-timed rhythm, where stressed syllables tend to occur at regular intervals. That means that the syllables might vary in length since there might be a varying number of syllables between stresses. English is a stress-timed language. In the following Spanish sentence syllables have the same length and occur at regular intervals:

\section{'Quic'ro 'que 'ven'gas 'al 'mé'di'co 'con'mi'go 'ma'ña'na}

In the equivalent English sentence, syllables vary in length but stressed syllables occur regularly:

\section{I 'want you to 'come with me to the 'doctor's to'morrow}

In English, rhythm is organized into feet (Abercrombie 1964). The foot begins with the stressed syllable and includes all the unstressed syllables up to the next stress where a new foot begins. The above English sentence has four stresses and consequently four feet. Using slashes to indicate foot boundary we could represent feet as follows: $I$ / 'want you to / 'come with me to the / 'doctor's to / 'morrow. The beat at the beginning of the foot might be silent, we mark this silent beat with a caret $($.$) .$

No language is purely stressed-timed or syllable-timed but tends to behave more like one or the other pattern. Delattre argues that German, for instance, takes a position midway between English and Spanish with respect to rhythm. Catalan seems to be a similar case.

Rhythm is also tempo dependent. The faster the speech, the more stressed-timed the rhythm (Angenot et al.). Thus, Spanish or Portuguese, said to be syllable-timed languages, become more stressed-timed when spoken at a fast rate, although vowels keep their distinctive quality. Thus, the following Spanish and Brazilian Portuguese sentences uttered at a fast speaking rate might result in a rhythmic pattern basically stressed-determined:

Claro que voy a hacer geografía

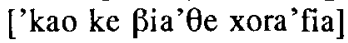

O que e que tu vais fazer?

[kek'tvaf'ze]

The basic differences between syllable-timed languages (such as Spanish) and stressed-timed languages (such as English) are: 
syllable-timed

1. wcak vowel reduction

2. simple syllable structure

3. proportional effect of tempo

4. absence of secondary stress

5. metrical system of a syllabic type

\section{stressed-timed}

1. strong vowel reduction

2. complex syllable structure

3. non-proportional effect of tempo

4. presence of sccondary stress

5. metrical system of an acentual type

1. In languages such as Spanish unstressed vowels suffer a weak vowel reduction since every syllable is allotted virtually the same amount of time to be produced. In English unstressed syllables have little time to be produced in order to keep the rhythmic beat on the stressed syllables. Thus, there is a strong reduction in vowel quality due to the undershoot phenomenon: in the short time allotted for the pronunciation of unstressed vowels the articulators do not achieve the vowel target, resulting in the centralized vowels $[\partial, \mathrm{i}, \mathrm{u}]$.

2. The reduction and subsequent elision of unstressed vowels have resulted in a large amount of consonant clusters and a complex syllable structure in English.

3. In English, speaking rate (fast vs slow speech) does not affect the duration of stressed and unstressed syllables proportionally. In Spanish, speaking rate effects on the duration of stressed and unstressed vowels is roughly the same.

4. Stress-timed languages tend to have secondary stress in words (or to introduce rhythmical stresses in longer sequences) to avoid long sequences of unstressed syllables and to keep the rhythmic beat. In English no stressed syllable in a word can be preceded by more than two unstressed syllables in succession, a secondary stress is introduced (e.g., clarifi' cation, re,conside'ration, varia'bility). After the stressed syllable there may be up to three unstressed syllables, but only in words with certain suffixes (e.g. ad'ministrative, 'candidacy).

5. In syllable-timed languages the syllable occurs at roughly regular intervals of time and the syllable is the rhythmical unit in verse (thus, Spanish verse is referred to as 'octosyllable,' 'decasyllable,' etc.). In stressed-timed languages it is the stress which occurs regularly and the metric system is based on the foot (thus, English verse is referred to as iambic, trochee, anapest, etc., which refer to different stress patterns of the foot).

\subsection{Isochrony}

In English, stresses occur at roughly regular intervals of time, and therefore all feet tend to be of equal duration or isochronous. Since feet take roughly the same amount of time to be produced and the number of syllables in a foot might vary, it follows that the length of syllables must also vary. If a foot with, say, 4 syllables takes the same amount of time to be pronounced as a foot with one syllable, then each one of the four syllables must be shorter than the one. Thus, if there are no intervening syllables between two stresses ( 1 below), the syllable which stands alone in a foot will tend to be stretched in time. If there are a number of intervening unstressed syllables ( 2 below), the stressed syllable will be made shorter, and the unstressed syllables will be squeezed together 
between stresses and they will suffer important phonetic reductions such as vowel weakening, elision, assimilation, haplology, etc.

The time adjustments in syllable length due to stress can be graphically represented as follows:
(1) / 'P a t / g o e s /
(2) /'Pat should have /'g o n e/

All feet in (1) and (2) will tend to have the same duration independent of the number of syllables. In order for that to be the case Pat in (1), which stands alone in its foot, will be longer than Pat in (2), which will be pronounced with a shorter vowel to allow more time for the unstressed syllables in the foot. Notice also the phonetic reductions of the unstressed syllables in (2), [Səcəv], to keep the beat on the following stress. Even though isochrony, or the regular occurrence of stresses, might not be perfect, there is evidence that English speakers unconsciously aim at isochronicity in the production of speech since they make adjustments in the length of sounds, as has been demonstrated.

Not all types of English speech are equally isochronous. The more organized the speech, the more isochronous it will be. Thus, verse and nursery rhymes are more isochronous than prose. And prose read aloud or formal speech is more rhythmical than conversational speech, which may be full of pauses, «uhms and errs», false starts and other interferences due to memory failure, lack of planning, etc. Thus, isochronicity seems to be a gradient feature (Crystal).

Another consequence of the stress-timed and isochronous nature of English rhythm is the existence of weak forms. Since content words are usually given prominence in the utterance, grammatical words will tend to be unstressed. As unstressed syllables they cluster around a stressed word or syllable within a foot or rhythmic group. Thus, grammatical words are squeezed in order to fit into the constant time interval between two stressed sy llables. This is so common in English that many grammatical words are said to have a full form used when the word is stressed for rhythmical, emphatic or contrastive reasons, and a weak form used when the word is unstressed and must be fitted between stresses. Consider the following grammatical words in stressed and unstressed position:

$\begin{array}{ll}\text { stressed } & \text { unstressed } \\ & \\ \text { 'Ycs, we 'are [a:] } & \text { 'What are you 'doing? [ə] } \\ \text { 'He's the 'person [hi:] } & \text { I 'don't 'know who he 'is [i] } \\ \text { 'Yes, you 'have [hæv] } & \text { I 'must have 'missed him [əv] }\end{array}$

\subsection{Rhythmic Alternation}

English rhythm, apart from being conditioned by the principles of isochrony and stress-timing, is characterized by the principle of rhythmic alternation; that is, in English weak and strong syllables alternate with one another. How is it that regular alternation of stressed and unstressed syllables results, if speakers do not choose their 
words according to their lexical stress pattern, but to the meaning they want to express and the form in which they want to couch this meaning? It seems that once the lexemes of an utterance have been selected, a set of rules (syntactical, morphological, phonetic and rhythmic) are applied to the utterance to determine its phonetic realization. Thus, a structure which does not observe the stress alternation principle (because too many stresses appear next to each other, or there are long sequences of unstressed syllables) will be modified by the rhythm rules to conform more closely the ideal rhythmic alternation.

1. If a series of content words appear next to each other, some stresses are dropped. There is a stress on each of the following content words: 'John's / 'friend /'wants /'get l'home /be'fore /'midnight; but some of these stresses, usually stresses on alternate words, are dropped when these words occur in a sentence such as: 'John's friend 'wants to get 'home before 'midnight. Tap with your finger at each stressed syllable while saying this sentence and you will find it quite natural to tap at the syllables marked as stressed. Similarly, if an utterance contains a succesion of three stresses, as in ' $B$ /' $B$ I'C ; 'big /'blue/'eyes; 'five l'eight /'two, the intermidiate stress tends to be dropped in order to achieve a more regular alternation: ' $B B$ ' $C$, 'big blue 'eyes, 'five eight 'two.

2. If an utterance consists of a succession of unstressed function words, e.g. he should have been here 'earlier, stresses are added to produce a more regular rhythm: 'he should have 'been here 'earlier. Similarly, the rhythmical stressing of if and as in initial position when followed by unstressed syllables, as in:

'If you are 'right, we should be 'getting there 'soon

'As a 'child he 'studied 'English

but not in medial position when next to another stress:

'We should be 'getting there 'soon if you are 'right

$\mathrm{He}$ 'studied 'English as a 'child

shows the tendency to distribute stresses rhythmically. Note that if and as are not likely to be stressed when immediately followed by a stressed syllable:

As 'Hcad of De'partment, I 'can't a'llow you to 'do

If 'worse comes to 'worse, we'll 'just 'drop it

There are constraints on stress addition and deletion. Stresses cannot be deleted just anywhere. Thus, in the above utterance John's friend wants to get home before midnight, the stresses on John/home/midnight cannot be deleted though others can. Similarly, stresses cannot be added just anywhere. If an extra stress is to be added in 'leave it in the 'car, due to a very deliberate and slow speaking rate, it cannot be added on the determiner, but must be added on the preposition: 'leave it 'in the 'car. Based on evidence of this kind Giegerich (46) suggests a hierarchy of stressable words.

3 . If two stresses are next to each other in a phrase, e.g. a,Japa'nese 'student. , after'noon 'tea, the first stress is moved to the preceding strong syllable: 'Japanese 'student, 'afternoon 'tea, to space out the stresses. 
The alternation of rhythmical stresses in English is best described by rhythmic hierarchies and metrical grids (Selkirk). In the following grid all syllables at the lowest rhythmic level (1) are marked with $x$, all strong syllables at level (2) with another $x$, and the lexical stress in each word by another $x$ at level (3). Phrasal stress is marked by another $x$ at level (4). The stresses in this utterance are represented as follows:

(2) $x \quad x \quad x$

(1) $\mathrm{x} \times \mathrm{x} \times \mathrm{x}$

Japanese student

$\begin{array}{llll}(4) & x & & x \\ (3) & x & x & x \\ (2) & x & x & x \\ (1) & x & x & x\end{array}$

Japanese student

If two stressed syllables are immediately next to each other on an upper level, with no intervening beats at the level below, there is a "stress clash» and stress shifts towards a leftmost strong syllable (at least at level 2). Thus, ,Japa'nese 'students becomes 'Japanese 'students, but be'tween 'cars does not become *'between 'cars, because the first syllable in between is not a strong syllable.

To sum up, the factors that contribute to maintain a regular rhythm in English are of two kinds. (1) There are those which affect the distribution of stresses to ensure rhythmic alternation:

a. dropping of some stresses to prevent too many stresses coming together, eg. 'nice 'old 'book $\rightarrow$ 'nice old 'book;

b. stress addition to avoid a long succession of unstressed syllables, e.g. he should have 'done it him'self $\rightarrow$ 'he should have 'done it him'self;

c. stress movement to a preceding strong syllable if two stresses are next to each other: Heath'row 'airport $\rightarrow$ 'Heathrow 'airport.

(2) There are those which affect adjustments in the length of sounds to keep a constant time interval between stresses.

a. Durational variations in the stressed syllable depending on the number of unstressed syllables in the foot. For example, reduction in vowel length when unstressed syllables follow. Compare the decreasing duration of the stressed vowel in 'lead, 'leader, 'leadership.

b. Reduction processes that affect unstressed syllables: vowel reduction, consonant weakening, elision, assimilation, haplology. For example, probably ['probəbli] $\rightarrow$ ['pra:bli], solicitor [sə'lisitə] $\rightarrow$ ['slistə].

c. Weak forms.

\section{Practising Stress and Rhythm}

The materials for practicing stress and rhythm will necessarily involve longer stretches of speech. It is convenient that the words and phrases used for practice should be well within the capacity of the learner and communicatively meaningful. Although it is the case that various degrees of stress can be distinguished, for the practice of rhythm it is only necessary to consider two types of syllables, stressed and unstressed. 
The use of standard materials for the practice of stress and rhythm (nursery rhymes, counting games, limericks, etc.) will not be considered here since they are available in most pronunciation manuals. We will consequently consider some basic exercises which encourage the adequate pronunciation of stressed and unstressed syllables.

1. Word stress and phrase stress. Spanish learners tend to produce unstressing in single polisyllabic words ('yesterday) more adequately than in sequences of words ('yes, he said). This is because in Spanish words have one main stress. In contrast, every single word in Spanish, be it a content or a function word, has a word stress in connected speech, and this tends to influence their English pronunciation. To avoid assigning stress to each word, practise phrases with the same stress pattern as single words till both are uttered exactly with the same rhythm. The following pairs of words and phrases should have the same rhythmic structure:

Two syllable words:

'David - 'take it

'city - 'give me

'over - 'told her

o'bey - the 'boy

a'shamed - a 'name

u'nique - you 'need

Three syllable words:

'passages - 'come with me

be'lieving - I've 'seen him

ciga'rrette - at the 'door

Four syllable words:

'category - 'give it to me cer'tificate - I 'wanted to expla'nation - you should 'do it this after'noon - I've got to 'go 'beautiful - 'look at it
con'sider - at 'Christmas
under'stand - switch it 'on

2. Find phrases that have the same stress pattern as the following words:

Example: im'pression ( ' ${ }_{-}$): to 'get it, at 'random, be'tween us

\begin{tabular}{|c|c|c|}
\hline $\begin{array}{l}\text { 'Wednesday }\left({ }_{-}\right) \\
\text {'country }\left({ }_{-}\right)\end{array}$ & $\begin{array}{l}\text { per'haps }\left({ }^{\prime}\right) \\
\text { a'gain }\left({ }_{-}\right)\end{array}$ & $\begin{array}{l}\text { nine'teen }\left(C^{\prime},-\right) \\
\text { al'though }\left(C_{-}\right)\end{array}$ \\
\hline $\begin{array}{l}\text { 'pcacefully }\left({ }^{\prime}\right. \\
\text { 'manual }\left({ }_{-}\right)\end{array}$ & $\begin{array}{l}\text { e'leven }\left(C_{-}^{\prime}\right) \\
\text { im'portant }\left({ }_{--}\right)\end{array}$ & $\begin{array}{l}\text { scien'tific }(,,-) \\
\text { am'bitious }(,-)\end{array}$ \\
\hline
\end{tabular}

3. Find phrases or sentences with the same distribution of stresses as the following:

'What's the 'time?

'Mary's 'here 'characterize - 'Sarah did it pho'tography - I 'told them to uni'versal - he was 'cheating superim'pose - I would have 'come 
'How d'you 'do?

He's 'learning 'English The 'man is 'coming The 'doctor 'told us
He 'wanted 'more

The 'phone is 'ringing

They 'couldn't 'get it

He 'went a'round it

'What would you 'like to 'do?

'This is a 'nice old 'book

'When do you 'Icave for 'school?

4. Practising unstressing in function words. Read the following strings of content words with an even rhythm. Then supply function words to turn them into full sentences and read them again with the same rhythm. Be sure to use weak forms where appropriate for your added function words. Alternate the two versions, making sure that the function words do not alter the rhythm:

1. 'think 'like 'dress

2. 'wait 'John 'hour

3. sub'let 'house 'month 'summer

4. 'take 'children 'school every 'morning

5. 'make 'date 'Pat 'wcek

6. a'rrive 'Spain weck'end

7. 'want 'Icft a'lone

8. 'possible 'go 'bike

9. 'think get 'on 'well

10. 'have 'mecting ' 10 o'clock 'Tuesday

5. Isochronicity of English rhythm. English rhythm is not perfectly isochronous. However there are different factors that tend to make it nearly isochronous. To practise isochronicity, first snap your fingers or tap your foot at a regular rhythm. Then try to make the stressed syllables in the following sentences coincide with the beats as you read the sentences (leave two beats between sentences):

1. 'Rhythm is a 'crucial 'feature of 'English

2. I 'dont 'think he 'wants to 'come

3. 'How are you 'doing?

4. I'm 'doing O'K, 'thank you

5. 'When we 'left it was 'raining

6. 'He should have 'gone him'self, but he 'couldn't 'make it

7. I'll 'have 'bacon and 'eggs, 'please

8. 'What a 'mess you've 'made

9. 'Will you 'please 'stop that

10. 'These are 'nice 'shoes you are 'wearing 
6. To practise the stressed-timed rhythm of English combine items from the following columns:

12

'Marcia

'David'

'Nobody

The 'woman

'Linda
2

'wrote to

told

con'sulted

in'formed

'bullied
3

the di'rector

'Peter

the 'manager

'everybody

my 'brother
4

im'mediatcly

at 'once

of 'course

'surely

you 'sec

7. Stress-timing. Each of the following sentences has two stresses, even though the number of unstressed syllables varies. As you say each sentence tap a table twice on the stressed syllable, keeping the strokes at a regular beat.

a

The 'cat is 'big

The 'tiger is 'big

The 'elephant is 'big

d

'Peter 'talks

'Peter would 'talk

'Peter would have 'talked

'Peter would have liked to 'talk $\mathrm{b}$

The 'cat is 'big

The 'cat is 'happy

The 'cat is 'happier

e

'Mary 'studies

'Mary is 'studying

'Mary will be 'studying

'Mary should have been 'studying
The'catis'big

The 'tiger is 'happy

The 'elephant is 'happicr

8. Provide pairs of sentences that show how the following words can have two different stress patterns:

Example: after'noon

I'll 'see you this after'noon

I have an 'afternoon 'class

outside

upstairs

sixteen

absolutely

Barcelona

out-of-date

9. Assigning sentence stress. (a) Place the stresses on the following dialogue.

(b) Read the dialogue tapping your finger on each stress to keep the rhythm.

Brian: Hello Mary. It's nice of you to come.

Mary: Oh, it's no trouble. I wanted to find out how you were feeling after the accident. 
B: I'm feeling fine, but I think it will take me a while to be recovered, I mean completely recovered.

M: Tell me about the accident. What happened exactly?

B: I was riding my motorbike and this old man stepped out in front of me so I had to brake suddenly.

M: He stepped out in front of you? But then it was his fault!

B: Yes, it was, but it doesn't change things. I fell off my bike, broke two ribs and he continued crossing the road as if nothing had happened. I think he didn't even realize he had caused an accident.

M. Oh, that's awful!

B: Yes, it is. Well, tell me about yourself. How are you getting on?

M: OK. I'm preparing my orals and I'm very worried about getting a good grade. Otherwise, I won't be able to get into Law School.

B: Oh, you will get a good grade, don't worry. Look at me! I won't even be able to take my orals this term.

\section{Conclusion}

We expect to have shown the importance of stress and rhythm in determining the realization of segments, indicating the morphemic and syntactic function of elements, and structuring information in the sentence. It follows from this that stress and rhythm are basic for intelligibility, adequacy and fluency in speech and that they should be consistently practiced by foreign learners if possible in the early stages.

We have concentrated on the production side of English stress and rhythm, which will contribute to more intelligible speech. There is another aspect which we have not considered, which is how the practice of stress and rhythm helps to understand running speech. Since stress highlights the most important words in the message, a rhythmical approach to English pronunciation will help the foreign listener to concentrate on the meaningful words in the message and to strengthen the links between pronunciation on the one hand and grammatical structure and meaning on the other. This approach encourages the understanding of language as communication rather than a set of isolated segments (for a full discussion see Brown).

\section{Works Cited}

Abercrombie, D. «A Phonetician's View of Verse Structure.» 1964. Phonetics and Linguistics. Eds. W. E. Jones and J. Laver. London: Longman, 1973. 6-13.

Albrow, K. H. The Rhythm and Intonation of Spoken English. London: Longman, 1968.

Angenot, J. P. et al. «Aspects of Casual Brazilian Portuguese.» Sixth International Phonology Meeting. Krems, Austria, 1988.

Arnold, G. F. and O. M. Tooley. Say It with Rhythm. 2 vols. London: Longman, 1971-72.

Brown, G. Listening to Spoken English. London: Longman, 1977.

Bolinger, D. L. «Intonation and Grammar.» Language Learning 8 (1958): 31-117.

Classe, A. The Rhythm of English Prose. Oxford: Blackwell, 1939.

Crystal, D. Prosodic Systems and Intonation in English. Cambridge: Cambridge UP, 1969. 
Couper-Kuhlen, E. An Introduction to English Prosody. London: Arnold, 1986.

Delattre, P. «German Phonetics between English and French.» Linguistics 8 (1964): 43-55.

Fry, D. B. «Duration and Intensity as Physical Correlates of Linguistic Stress.» Journal of the Acoustical Society of America 27 (1955): 765-68.

. «Experiments in the Perception of Stress.» Language and Speech 1: 126-52.

Fudge, E. English Word Stress. London: Arnold, 1984.

Guierre, L. Drills in English Stress Pattern. London: Longman, 1970.

Giegerich, H. J. «On the Rhythmic Stressing of Function Words: A Modest Proposal.» Work in Progress 11 (1978): 43-51.

Kingdon, R. The Groundwork of English Stress. London: Longman, 1958.

Lieberman, P. «Some Acoustic Correlates of Word Stress in American English.» Journal of the Acoustical Society of America 32 (1960): 451-54.

O’Connor, J. D. Stress, Rhythm and Intonation. Madrid: Alhambra, 1959.

Pike, K. The Intonation of American English. Ann Arbor: U of Michigan P, 1945.

Selkirk, E. Phonology and Syntax: The Relation Between Sound and Structure. Cambridge, Mass.: The MIT P, 1984.

Solé, M. J. «Experimentos sobre la percepción del acento.» Estudios de fonética experimental. Ed. E. Martínez Celdrán and M. J. Solé. Barcelona: PPU, 1984. 1: 131-242.

Tibbits, E. L. English Stress Patterns: Practice Material. Cambridge: Heffers, 1967. 